\title{
Transition of the NSW Public Health Bulletin to Public Health Research \& Practice
}

\author{
Sarah Thackway ${ }^{\mathrm{A}, \mathrm{C}}$ and Sally Redman ${ }^{\mathrm{B}}$ \\ ${ }^{\mathrm{A}}$ Centre for Epidemiology and Evidence, NSW Ministry of Health \\ ${ }^{\mathrm{B}}$ The Sax Institute \\ ${ }^{\mathrm{C}}$ Corresponding author.Email: sthac@doh.health.nsw.gov.au
}

The NSW Public Health Bulletin has achieved much over the past 24 years $^{1}$ and there is a great deal to celebrate. To support an agile, contemporary, public health environment the Bulletin is about to enter a new phase in its evolution one that builds on its proud history and strongly positions public health for the future. The Bulletin will be renamed Public Health Research \& Practice and will strengthen its focus on supporting knowledge-driven policies and the provision of best practice public/population health services and programs in NSW and across Australia. This will be underpinned by original, policy-relevant research and articles on implementing and evaluating innovative NSW policies, services and programs. Editorial management and production will move to the Sax Institute and be overseen by an Editorial Board (Box 1).

Both the NSW Health and Medical Research Strategic Review $^{2}$ and the NSW Government Evaluation Framework ${ }^{3}$ emphasise the potential for research and evaluation to strengthen policy and practice across health. For this potential to be realised, new approaches to designing and conducting research and to sharing our findings will be required. We intend that Public Health Research \& Practice will become a key platform in using research to inform public health policy and practice across NSW and Australia more broadly.

The optimal generation and use of evidence will require many things. For example, strong evaluation embedded into the rollout of policies and programs will make the most of opportunities to learn what works and under what conditions. The NSW Government Evaluation Framework ${ }^{3}$ makes this clear saying:

Evaluation is a key tool to support evidence based policy and decision making in government, to help government learn and adapt to changing environments and as a tool for communicating and sharing valuable information. When planned, designed and conducted in accordance with good practice standards, evaluation can provide the necessary evidence to improve services and guide better resource allocation decisions.

Better tools and methods for the kinds of research that can inform practice will also be required - for example, how can we best consider factors like scalability ${ }^{4}$ and reproducibility? How do we best estimate likely real world costs and benefits? How can we harness technology to respond to emerging public health threats? And what can be done to provide control or comparison groups when randomised trials are not possible?

Co-creation of research where researchers, policy makers and practitioners work together to design, implement, interpret and disseminate research will be crucial to this effort. Each has important expertise to bring to the collaborative effort. Co-creation of research has the potential to result in rigorous tests of strategies in a timely way that could feasibly be implemented at the state or national levels.

Public Health Research \& Practice will strengthen the connection between research, policy and practice and support the population health workforce in NSW to find and use the best available evidence in the time available. ${ }^{5}$ We will actively seek papers describing research that has used a co-creation approach and is based in a 'real world' setting, and will be particularly interested in papers 


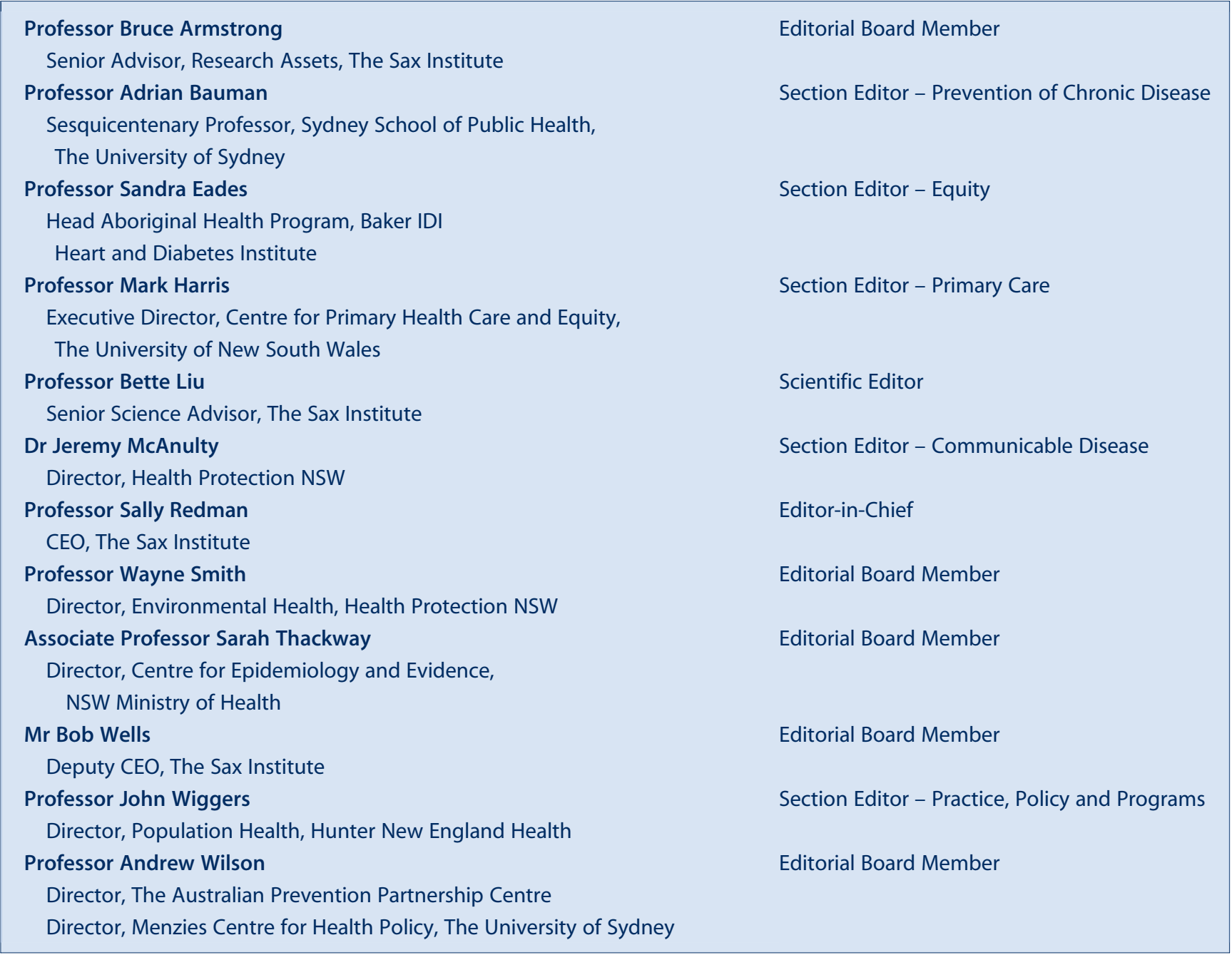

describing the evaluation of innovative policies and programs in the field. This will instigate a new stream of discussion to drive forward the development of methods that work more effectively to understand the impact of health issues, policies and programs in the field. NSW Health and the Sax Institute are excited about this new phase in the development of the journal and we are looking forward to working with researchers, policy makers and practitioners to further strengthen our investment into evidence-informed policy and practice.

\section{References}

1. Thackway S, Goldsworthy KM, Stickney B, Milat AJ. Reflections on 24 years of the NSW Public Health Bulletin. N S W Public Health Bull 2014; 24(4): 151-2.
2. Population Health Division, NSW Ministry of Health. NSW Health and Medical Research Strategic Review 2012. Available at: http://www0.health.nsw.gov.au/pubs/2012/pdf/ medical_strategic_review_.pdf (Cited 14 April 2014).

3. Department of Premier and Cabinet. NSW Government. NSW Government Evaluation Framework August 2013. Available at: http://www.dpc.nsw.gov.au/_data/assets/ pdf_file/0009/155844/NSW_Government_Evaluation_ Framework_August_2013.pdf (Cited 14 April 2014).

4. Milat AJ, King L, Bauman AE, Redman S. The concept of scalability: increasing the scale and potential adoption of health promotion interventions into policy and practice. Health Promot Int 2013; 28(3): 285-98. doi:10.1093/heapro/dar097

5. Lavis JN, Oxman AD, Lewin S, Fretheim A. SUPPORT Tools for evidence-informed health Policymaking (STP). Health Res Policy Syst 2009; 7(Suppl 1): I1. doi:10.1186/1478-45057-S1-I1 